Manuscript published in Computers \& Education 53 (2009) 343-354, doi:10.1016/j.compedu.2009.02.011

\title{
Gendering the ICT curriculum: The paradox of choice
}

\section{Jane Abbiss}

Abstract: This paper looks at the ICT (information and communication technology) curriculum in New Zealand secondary schools and gendered participation patterns in different specialist ICT subjects. New Zealand has a permissive ICT curriculum, comprising a variety of subjects and characterised by choice and variation in the curriculum in practice at the local level. The data that are reported include results of (i) a national questionnaire survey of secondary schools, and (ii) a qualitative case study conducted in a large, coeducational New Zealand secondary school and involving classroom observations and interviews with teachers and students. It is suggested that the permissiveness of the curriculum, which ostensibly caters for the needs of students by providing choices, may, in some circumstances, effectively reinforce gender stereotypes relating to computer interests and practices. This is a paradox of choice. Questions are raised about the nature of the ICT curriculum in New Zealand and how it may contribute to or challenge gender stereotypes, future curriculum developments and, more broadly, how we can account for persistent gendered participation patterns in ICT subjects in schools.

\section{Introduction}

In recent decades, education sectors internationally have been subjected to the powerful and pervasive economic imperative of the information age, manifest in the rhetoric of "knowledge economies" and "information societies". Within this

discourse, ICT education is positioned as an engine for national economies, a mechanism for creating prosperity, and a panacea for social inequalities. Computerliterate populations, it is argued, are essential to the economic and social health of nations, including New Zealand. Education assumes a pivotal role in economic development by preparing students for life and work in information societies; governments and other stakeholders promote ICT for its power to improve learning 
and to transform education (Kenway, 1998; Law, Pelgrum, \& Plomp, 2008; Lewis, Smith, \& Jenson, 2001; Pelgrum \& Anderson, 1999).

Within the New Zealand context, policy advisors argue that greater familiarity with and use of ICT in schools is necessary if New Zealand is to sustain a competitive economy and if New Zealanders are to be equipped to work and live in an information age (Butler, 1996; Ministry of Education, 2002; Sallis, 1990). Provision has been made within the sphere of ICT education for specialist ICT subjects in secondary schools and for integrating ICT across the various subjects of the curriculum in the belief that such developments will improve the worth and chances of students in a knowledge economy. The research that is reported herein relates to the first of these two different approaches to ICT education, that is, ICT as separate topics in secondary schools and it explores the gender implications of this provision.

The push for increased ICT competency has given rise across the decades to equity concerns that some groups, such as women and cultural minorities, may be left behind in the drive to create increasingly information-literate workforces. Both international and New Zealand literature describe historical inequities in males' and females' access to and use of computers in school and at home (Chen, 1986; Clegg \& Trayhurn, 2000; Durndell, Glissov, \& Siann, 1995; Hoyles, 1988), differences in attitudes and preferences for different computing practices (Beynon \& Mackay, 1993; Colley \& Comber, 2003; McKinnon \& Nolan, 1990; Mitra, LaFrance, \& McCullough, 2001), and gendered domains of practice and computing culture (American Association of University Women Educational Foundation Commission on Technology, 2000; Culley, 1993; Ryba \& Selby, 1995; Wajcman, 1991).

The gender inequities reported in the early literature appear to be ongoing. There are persistent reports, internationally and in New Zealand, of proportionately low numbers of females in computing education and computing careers (Anderson, Lankshear, Timms, \& Courtney, in press; Logan, 2007; O’Neill, 2003; United Nations Conference on Trade and Development, 2002) and even of a widening "digital gap" in employment among young males and females in the European Union (Seybert, 2007). Although there is some evidence of a reduction in digital gaps occasioned by the use of new media such as instant messaging and text messaging, 
inequities in use of ICT between males and females appear to be ongoing (Davis, Broege, Steinmetz, \& Raman, 2006).

Such reports of persistent differences reinforce broad concern that females are disadvantaged in both ICT education and the ICT workforce (Margolis, Fisher, \& Miller, 2000; Ryba \& Selby, 1995). Young people may use new technology in daily life, express confidence in using this technology, and recognise male and female competence in daily use, but there are persistent gendered constructions of expertise and ideas about what males and females "do" with computers, and these are reflected in gendered subject participation patterns. These gender constructions, moreover, relate to particular computer practices and position males as computer experts (Abbiss, 2006; Johnson, 2006). They also relate to the privileging of particular types of knowledge and academic subjects over others (Gilbert, 2005), which, in the ICT field, has valued male-dominated subjects over those historically dominated by females (Clegg, 2001; Cukier, Shortt, \& Devine, 2002). The perceived gender gap and disadvantage is thus defined by differences in computer interest, skill and orientation, and career potential.

Some commentators argue that cyberspace culture will increasingly reflect the desires and sensibilities of males to the exclusion of females if boys continue to be the inventors and girls the users of things that boys invent. They go on to claim that if females are to avoid being disempowered and disadvantaged in a technological age, then they must be involved in computer software and systems design (Margolis \& Fisher, 2002; Selby, 1995). The schooling sector is implicated as a conservative force that helps maintain gender inequities and as a potential force for change and the dissolution of difference and inequity.

Given the dramatic increase in the availability of computers and their ubiquity in daily life over the last decade, we could assume that equity concerns relating to participation in ICT courses at school and technological influence in the workplace have largely dissolved. However, the prevalence of computers, vastly improved access to computer technology, ICT schooling initiatives, and the proliferation of ICT subjects and provision of choices of subjects in New Zealand schools seem, according to aforementioned literature, not to have broken down gender differences in computer 
interests and uses to the extent some of us may have expected or wished. Simple explanations relating to the provision of computers and ICT courses are inadequate to explain persistent gender differences. What, then, might be some other factors or reasons? This paper explores gender patterns and trends in the ICT curriculum relative to secondary students' subject choices and the nature of the curriculum at national and local levels with the aim of offering possible explanations for gender inequities in the secondary schooling sector.

\section{Method}

The findings reported herein derive from qualitative research relating to gender, curriculum culture and students' experiences of specialist ICT subjects ${ }^{1}$ in the New Zealand context. Grounded in the phenomenological tradition, where priority is given to lived experience and the production of in-depth descriptions of those experiences (Creswell, 1998; Holstein \& Gubrium, 1998; Jackson, 1996), the study was concerned with exploring the nature of students' experiences in the naturalistic setting of ICT classrooms. The purpose was theory generation, which involves drawing connections from the ground up rather than searching for data to prove or disprove a hypothesis as in the positivist quantitative tradition (Bogdan \& Biklen, 1998; Tashakkori \& Teddlie, 2002). The methodology, which drew on constructivist-interpretivist and feminist frameworks (Denzin \& Lincoln, 1998b), acknowledged that meaning or understanding is developed through people's experiences in social contexts and placed gender relations at the centre of the inquiry.

Quantitative and qualitative methods were employed in the form of (i) a national survey of subject options and student participation in specialist ICT subjects, and (ii) an exploratory case study at Kahikatea High School (a pseudonym), within what is essentially a qualitative research project in order to answer the following research questions. These questions (one main and a series of three sub-questions) were broadly framed, consistent with a qualitative approach. The main research question asked: Do students experience a gendered curriculum culture in specialist IT classes in New Zealand? The sub-questions were as follows: (i) What is the structure of the formal New Zealand IT curriculum at national and local levels? Is the formal IT

\footnotetext{
${ }^{1}$ In specialist ICT subjects, computers comprise both the mode and the topic of study.
} 
curriculum gendered? (ii) How do teachers of the case study classes define specialist IT subjects in practice? Does this contribute to a gendered IT curriculum culture at Kahikatea High School? (iii) What are students' experiences of specialist IT subjects in the case study classes? What part does gender play in students' experiences of specialist IT subjects?

This article does not report the totality of the findings from the research, but focuses on one issue that emerged from the data and associated theorising, based in the rich descriptions generated of curricula in practice in particular specialist ICT classes and individual students' experiences of learning in those classes. The structure of this article, which sets out the findings (and discussion of these) relative to the survey and then the case study, reflects the research process by presenting the "problem" and context evident in the research questions and then offering a more in-depth and focused exploration of the issues.

The survey was designed to describe the nature of the curriculum implemented in schools and participation in ICT subjects and to provide a context for the subsequent case study exploration that was the main focus of the research. It constitutes descriptive trend data. The questionnaire data were collected in 2000 , and the case study observations and interviews were conducted in 2001. The national survey data have been updated and supplemented from recent Ministry of Education statistics. The data present a snapshot of students' participation in specialist ICT courses early in the new millennium and place the case study "moment in time" in the context of current participation trends. The survey sought information that would allow description of general patterns in subject offerings and student enrolments in specialist ICT subjects. It drew on Ministry of Education statistics and an independent questionnaire to schools that asked for detailed information on curriculum arrangements at the local level.

The questionnaire was sent to all New Zealand schools with students in the Years 9 to 13 age range, 446 schools in total. The return rate was $44.39 \%$, comprising 198 schools. This may not appear to be a high return rate, but it was pleasing given an apparent weariness from schools in responding to questionnaires and was the result of two mail-outs, with the second one sent to schools that did not respond to the initial 
request. Although the responses came from schools of different character, the majority of them were from secondary schools Years 9-13 (58\% of the return), state or state integrated schools (91\%), and co-educational schools (70\%). Responding schools covered the socioeconomic spectrum, thereby representing the full range of decile ratings, although Decile 1 (low socioeconomic rating) schools provided under half the number of responses received from any of the other decile groups.

Although, in respect of gender classification, the majority of responding schools was co-educational, a comparison of national statistics on the proportion of co-educational and single-sex schools in New Zealand showed that the number of co-educational schools was under-represented and that the number of single-sex girls' schools was over-represented in the questionnaire returns. The percentage of schools of different type and authority in the sample group was very similar to the proportions in the national school population.

The case study provided a means for investigating in greater depth the gendered participation patterns in specialist ICT subjects that emerged in the survey data-in this case in relation to the curriculum at Kahikatea High School (KHS). ${ }^{2}$ The school is a large, state, urban, co-educational secondary school. It is conventional in the sense that, at the time of the study, it had not received any extraordinary funding support for ICT or engaged in any unusual ICT initiatives. The case study was multi-faceted and comprised three specialist ICT classes, Year 10 and Year 12 text and information management classes (10TIM and 12TIM) and a Year 12 computer studies class (12CPS). The case study was collective in nature, in that each contributing class comprised an instrumental case study (Stake, 1998). Focusing on several classes allowed exploration of the general phenomena of students' experiences and the gendering of curriculum, while at the same time maintaining the integrity of the cases and recognising the uniqueness of setting and curriculum context for each class. Within each class, a number of students constituted what Yin (1994) calls embedded case studies, or sub-units of analysis.

\footnotetext{
${ }^{2}$ Pseudonyms are used for the names of the school and for participating teachers and students to protect confidentiality and maintain anonymity.
} 
There were sixteen student participants (embedded cases) from 10TIM and 12CPS, comprising equal numbers of males and females, and six girls from the all-female 12TIM class. Data included audio records of teacher and student conversations and notes from lesson observations, interviews with class teachers, and interviews with pairs of students from each class, 22 students in total, who constituted embedded cases in the three case study classes.

Each participating student was the focus of two classroom observation sessions, at different times of the year and in the context of different units of work, and one interview towards the end of the year. The instruments included an observation record that tracked a student's activity in relation to engagement with computers and social engagement in the classroom. It included snippets from students' conversations and provided counter-references that allowed the activity to be matched against the audio records. The observation record also included a column for observer comment, for questions and initial interrogation and interpretation of the data, and a map of the classroom that located the participating students in the physical and social space.

Semi-structured interview schedules were developed and used for teacher and student interviews. The questions for teachers related to class organisation, teacher background, learning focus and class dynamics, including gender. The questions for students focused on attitudes to computers, subject choices, computer use, skills and knowledge, teaching approach, aspirations, perspectives on gender, and their responses to having recording equipments and a participant observer in the class.

The analysis of case study data followed the qualitative interpretation process outlined by Denzin and Lincoln (1998a) that involves field text creation, the re-creation of field texts into working interpretive documents, and the production of the public text or final product. Multiple readings of the field texts were undertaken, with the researcher seeking out signals or clues in dialogue and observed interactions that explained how and why the curriculum was organised in particular ways and illuminated the nature of students' experiences in specialist ICT classes. More specifically, this process meant looking for factors that influenced the meaning or constructions students made of their experiences, including the judgements they made about computers and computing and about the specialist ICT courses in which they 
were engaged. Key points were highlighted and, in line with the research questions, labelling of data focused on activities and interpretations and on perspectives or ways of thinking that gave meaning and helped to define how teachers constructed the curriculum in practice and students' experiences of the curriculum.

This analytical approach led to the production of detailed descriptions of how the curriculum is constructed in different classes and individual students' experiences of specialist ICT courses. Each of these comprised a qualitative narrative, and the qualitative writing was part of the analytical process as it permitted a way of organising thoughts, clarifying ideas, and sorting out relationships in the data, thereby deepening the analysis and making sense of the research process and the emerging data (Coffey \& Atkinson, 1996; Holliday, 2002; St. Pierre, 2002). Quotations were included liberally in the narratives to maintain the participants' voices and to reveal their thinking and the constructions placed on their experiences. The final product was a meta-story - a hybrid narrative resulting from the reshaping of others' stories and interpretations of those stories.

Trustworthiness in the research, which relies on the accuracy and comprehensiveness of the data and the credibility of inferences drawn, was achieved through prolonged engagement and persistent observations in the field, triangulation of data sources, and the generation of thick description in the field texts and production of detailed narratives. These are indicators of worth, although not the only indicators, as they offer strategies for ensuring rigour in qualitative research (Anfara, Brown, \& Mangione, 2002; Bogdan \& Biklen, 1998; Tashakkori \& Teddlie, 2003). In qualitative research, there is not the assumption that the researcher knows enough to recognize important concerns prior to his or her engagement in the research. He or she may therefore use the study to learn what the important questions or issues actually are (Bogdan \& Biklen, 1998). This article illuminates and elucidates in a meta-story an important issue that emerged from the research, namely the gendering of the ICT curriculum and the paradox of choice that this presents. 


\section{Survey Findings}

\subsection{ICT subjects and curriculum context}

The New Zealand ICT curriculum is a liberal and permissive curriculum that has developed in a largely ad hoc manner (Brown \& Chamberlain, 2003). In respect of ICT at the senior secondary level, subjects were historically defined by examination prescriptions and national guidelines for the School Certificate and Sixth Form Certificate qualifications. More recently, they have been defined by the requirements for national certificates on the National Qualifications Framework (www.nzqa.govt.nz/framework) and the assessment mechanisms of achievement and unit standards. Information and communications technology is identified as a "technological area" in the national curriculum for technology (Ministry of Education, 1995, 2007), spanning Years 1-13 and Levels 1-8 of the curriculum. However, schools have had and continue to have the flexibility to define their own curriculum, within national guidelines and policy structures. National curriculum and qualifications requirements are interpreted and given structure and form at a local level in the subject offerings of individual schools and in the specific content of courses defined at the classroom level.

\subsection{Range of and variety in ICT subjects and enrolments in subjects}

The survey of ICT subjects in New Zealand schools exposed considerable variety in the curriculum in practice. Statistics of historical enrolments in nationally recognised subjects at intervals over a 15-year period revealed an expansion in the type of computer-based courses offered in New Zealand schools throughout the 1990s in both the computing and commerce traditions (see Table 1). In 1990, there was only one nationally recognised specialist ICT course-Year 12 computer studies. By 2000, however, there was a variety of computer-based subjects across a range of levels, witnessed by the expanded classification of subjects used by the Ministry of Education. However, the specific nature of subjects or courses in each classification is unclear, such as those within computer-related studies.

[Take in Table 1 about here] 
In respect of numbers and the nature of enrolments, Ministry statistics show that through the 1990s and on into the new millennium, computer studies has been the most popular specialist ICT subject in Years 12 and 13. However, text and information management and typing has become more popular in the younger years, and the subject initially called information technology, but now more typically called information and communication technology, has shown increased popularity at the younger levels. Some subjects tend to have greater numbers of classes in the younger secondary schooling years, including information technology, and others have greater numbers at the senior years, most notably computer studies at Year 12. This pattern is not surprising given that computer studies traditionally has been a subject for national qualifications at the senior level, possessing nationally defined subject guidelines relative to Sixth Form Certificate at Year 12 and, from there, relative to the National Certificate in Educational Achievement (NCEA). The statistics also show that schools position some subjects as introductory, entry-level computer-related courses but give greater prominence to ICT-related courses at the senior school level where students typically select the subjects they will study for national qualifications.

The results from the national questionnaire to all schools revealed a more complex picture of subjects and described a proliferation of specialist ICT courses being taught in schools at the beginning of the millennium (see Table 2). The expansion of the number and type of specialist ICT subjects has blurred the boundaries between domains and created considerable potential for overlap between courses. Various names are given to ICT courses in secondary schools, as revealed by the titles reported by schools. There is a multiplicity of course combinations, and the nature of particular courses can vary considerably between schools. For example, what is called computer studies in one school may be very similar to information technology or text and information management in another school. It was difficult with the questionnaire responses to classify some courses as belonging to one or another discipline or subject tradition.

[Take in Table 2 about here]

Adding to the "confusion", subjects called information technology and information and communications technology are administered by different departments in 
different schools and may employ a diverse range of software applications. In specific examples from the questionnaire responses, one Year 10 information and communications technology course in a school was using desktop publishing, word processing, spreadsheet, PowerPoint, and Microsoft Office applications, while another school was utilising QBasic programming, graphics, and spreadsheet software in its Year 10 course. A different school again bases its Year 10 information and communications technology course on worldwide web and HyperStudio applications. Programming and computer-aided design applications also feature at different levels and in courses identified by a range of names - computer studies, computer science, technology, graphics, and design.

In summary, although the specialist ICT curriculum presented in schools is potentially highly varied, and the combinations of subjects and content emphasis have unique forms at school level, there does appear to be a national trend towards merging computer subjects and traditions as new courses are developed and implemented at school level.

\subsection{Gendered participation patterns}

What, though, is the gender picture? National statistics of enrolments in specialist ICT subjects from the different domains present a picture of gendered participation patterns (see Table 3). Subjects from the computing domains have mixed-gender followings, but those associated with commerce and office practice appear to be strongly and persistently gendered, as they are heavily dominated by females. The proportion of males enrolled in computer studies at the different levels tends to be higher than the proportion of female enrolments, but this difference is within a relatively few percentage points. Females outnumber males in some years at some levels.

[Take in Table 3 about here]

The enrolment statistics for the subject ICT show a similarly complex picture, with subtle variations in gender balance. Female enrolments exceed male enrolments at most levels, but not at all levels in all years. In contrast, the subject text and information management is clearly dominated by females at all levels, as are other 
commerce and office-practice-related subjects. However, the proportion of males in text and information management is higher in Years 9 to 11 than in Years 12 to 13.

It appears, then, that the gender balance in enrolments varies with different levels and by subject. The national enrolment statistics suggest that computer studies and related courses have similar appeal to males and females but that text and information management and other commerce and office-related subjects have far greater appeal to females than to males. There are thus persistent gender-based differences in national participation patterns between specialist ICT curriculum domains. Student participation figures from the questionnaire results (Table 4) show similar patterns to those in the Ministry of Education statistics. Based on the enrolment figures for the five most popular specialist ICT subjects, as reported by respondent schools, it is apparent from the table that courses labelled computer studies have a stronger male following. In contrast, those labelled text and information management have far greater numbers of female than male enrolments. However, there are variations in the male/female balance for different cohorts. For example, of the 3,175 students enrolled in Year 9 text and information management, 31\% are male. This compares with 24\% of Year 11 text and information management enrolments and 14\% for Year 12. In contrast, females make up 15\% of CPS enrolments in Year 11 and $40 \%$ of those in Year 12.

[Take in Table 4 about here]

There are also distinct differences in the proportions of males and females participating in different subjects. For example, of the total number of Year 12 students participating in the five most popular courses, $60 \%$ of the males are involved in computer studies, compared with $35 \%$ of the females. At Year 13 and higher, the proportions are $70 \%$ and $31 \%$ respectively. This pattern contrasts with text and information management where the balance is reversed. Six percent of Year 12 males participate in text and information management, compared with $31 \%$ of the females. The figures are $6 \%$ and $25 \%$ respectively for Years $13+$, and $42 \%$ and $80 \%$ for Year 11. It appears, then, that year level plays a part in the gendering of the curriculum. For example, text and information management has a greater following among males 
during the younger years of secondary schooling. The female following for computer studies is strongest in Year 12.

The questionnaire results also revealed that the type and number of specialist ICT subjects varies with the gender mix of a school. A trend within single-sex girls' schools is to offer more courses from the commerce and office practice traditions, which include text and information management, keyboarding, word-processing, and business studies/administration. In contrast, boys' schools markedly favour computing courses over those from other traditions. Ministry statistics since 1995 confirm that, proportionally, single-sex girls' schools have more students taking text and information management relative to computer science/programming or computer studies and vice versa for single-sex boys' schools (see Table 5). Co-educational and single-sex girls' schools display similar patterns for enrolments in ICT subjects. It is not known to what extent these differences in subject offerings and student enrolments are a function of student demand or a reflection of restricted subject offerings in different schools.

[Take in Table 5 about here]

Over the years, the data also show a trend for more girls to participate in computing courses and for more boys to take text and information management courses. Subjects merge, disappear, or are redefined, blurring the boundaries between the categories reported in national statistics and the subject offerings in schools. Nevertheless, marked gender differences in student enrolments in different types of specialist ICT subjects persist in the new millennium. Although the statistics paint a picture of gender differences in participation patterns in terms of males and females respectively favouring different subjects, they do not explore reasons for the phenomenon or explain it. To find reasons, it is necessary to go behind the statistics to determine what is happening at the school level-the site where students make their subject choices and where teachers construct and implement the curriculum in practice. 


\section{Case Study Findings}

\subsection{Looking behind the patterns: Kahikatea High School}

The ICT curriculum at KHS comprises option subjects from computing and office practice traditions. Enrolments in the computer studies and text and information management courses at different year levels largely mirror national gender patterns. In the year of data collection, specialist ICT subject offerings comprised computer studies at Years 12 and 13 and text and information management for Years 9 to 12. Computer studies classes were mixed-gender groups, with similar numbers of males and females. Text and information management enrolments for the Years 9, 10, and 11 cohorts were mixed-gender, although males outnumbered females in Year 9 and vice versa for Years 10 and 11. Contrasting with this was the 12 TIM class, which comprised a self-selected all-female group.

Computer studies and text and information management courses at KHS at the time of data collection were similar in that both had a technocratic construction, meaning that they had a "how to" approach to learning about computers. In essence, these courses were introductory courses intended to familiarise students with commonly used computer applications. Units of work and lessons for both subjects were structured in similar ways, following a basic pattern whereby students were introduced to different applications, provided with instruction on particular functions, menus and commands, and then required to perform a range of exercises that gave them practice at using different features and that became more difficult as they progressed through the tasks.

The specialist ICT courses at KHS conformed to what Moursund (1997) termed a computer-as-tool model. In this model, the learning emphasis is on generic applications or tools that have applicability across disciplines. The content of the computer studies and text and information management courses at KHS comprised collections of applications and there was overlap between them. For example, the 12 TIM and 12CPS courses both included word-processing, databases, and spreadsheet applications. The most obvious differences were that 12CPS included basic programming and 12TIM retained a keyboarding/typing component.

In general, then, the data revealed only minimal difference between the various specialist ICT subjects at KHS, brought about through merging of traditions and 
overlap in content. There must be something, though, that sustains the gender differences in student enrolments. As detailed in the next section, this "something" related to construction of gendered domains of practice and gendered subjectivities that, despite the similarity and overlap between subjects, were maintaining a strongly gendered computing culture at KHS.

\subsection{Gendered domains of practice}

At KHS, the computer studies and text and information management subject areas in place at the time of the study reflected traditional and historically gendered staffing arrangements. All the teachers of text and information management courses were female and the teachers of computer studies were male. The two subjects were administered in different departments - the former in business studies, which had a female head of department, and the latter in the computer studies department, which had a male head. The image of the departments and the teachers' subject expertise and responsibilities is a gendered image-males in computer studies and females in text and information management.

The staffing arrangements at KHS appeared to reflect the particular historical circumstances surrounding each appointment. These arrangements had created domains of practice that reflected traditional gender interests and roles, albeit unintentionally. The network manager at the time of the study was male and had previous work experience in the computer industry. Mrs Keall, the teacher responsible for developing the text and information management courses and for teaching 12TIM, had worked in offices in a range of clerical and administrative positions before becoming a teacher. The other teachers involved in ICT had followed different paths. Mr Lucas, the 12CPS teacher and head of computer studies, had moved into computer studies in the early years of the subject's development because of his background as a social sciences teacher. He also had been instrumental in developing the applicationsbased computer studies courses at KHS, learning about the subject as he went. Mrs Nugent, the teacher of 10TIM, had tertiary qualifications in applied computing and previous work experience as an accountant. The different backgrounds of the teachers had equipped them with different knowledge and expertise, some of which transcended the discipline boundaries for the different specialist ICT subjects. 
However, their positioning in particular departments and teaching particular courses appeared to be maintaining and sustaining gendered domains of practice.

In general, these gendered domains of practice in the specialist ICT curriculum at KHS had been established through the gendered nature of the staffing for the different subjects and the gendered patterns of student enrolments in those subjects. At KHS, the specialist ICT subjects were thus located in gendered administrative domains: computer studies was the subject taught by male teachers and favoured by male students; text and information management had female leadership and a far stronger female following, especially at the senior level.

\subsection{Gendered ICT subjectivities}

What of the subjects themselves, and the way in which the teachers and students at KHS viewed them? Was it possible to discern something about these subjects that identified them as boys' or girls' subjects? Comments and observations by teachers and students of 10TIM, 12TIM, and 12CPS suggest that text and information management and computer studies were indeed seen to cater more for the perceived interests of one or the other gender.

The three teachers talked about $12 \mathrm{CPS}$ as a course designed to cater for a broad range of interests, for males and females, consistent with its utilitarian construction in the model of computer-as-tool. In one particular respect, though, 12CPS was thought to suit the interests of boys, and this was its programming component. In contrast, text and information management, within 12TIM in particular, was seen as a subject more suitable for girls because of its perceived emphasis on word-processing and keyboarding, activities that are associated with office practice and female work. The teachers described programming as a particular, but not exclusive, interest for boys. Girls were described as more reluctant, although not necessarily less able, programmers.

Mr Lucas: Um, especially when you get to programming, boys perhaps respond better to the programming section than the girls, but the girls often, are often surprised there that they actually enjoy the challenge.

And 
Mrs Keall: The boys seem to follow the computer studies a little bit more. They seem to want to get into the programming, whereas the girls don't do the programming quite so much. They are not quite so interested in that.

Mr Lucas foresaw 12CPS moving away from practices associated with office work and towards computer control. This development, he thought, would mean placing greater emphasis on operations such as programming and web authoring. It would also mean moving away from a construction of computer studies that Mr Lucas saw as being favoured by a particular group of females and towards a construction that catered for the interests of males.

Mr Lucas: We are moving away from the, if you will pardon the expression, the girl who is going to go into an office and just do a bit of typing, which is a group that we have had before, especially at Year 12, but we are finding at Year 13 we are getting more the ones that want to go in a bit more technical way because that's the way they see their interests going ... We are really looking at those people that want to go on to polytech or university and want a background in computing, because that's where we're finding a lot of students, especially the boys, are heading ... And so, to make full use of the new techniques of the Internet, programming especially, we are going to move that way.

Mr Lucas's thinking shows a clear association of office work and typing with female practice. He was somewhat disparaging in his view of this practice, evident in his reference to girls wanting to do "a bit" of typing. Word-processing is trivialised in the reference to it as "typing", which also carries undertones that it is dated or technologically unsophisticated. The suggestion is that the anticipated changes to the 12CPS course will better meet the needs of students, especially males. The observation that students want to pursue computing in "a bit more technical way" implies a wish to pursue applications associated with information systems and software engineering. This would position 12CPS as a more specialised computer course, moving it towards a computer science construction and a domain of practice that has been and continues to be dominated by males in higher education and the workplace.

Students' expectations of 12CPS differed. The boys in 12CPS who were interviewed were attracted to the subject because they thought it would teach them about how computers work, including technical aspects of computers' operations, hardware, and systems. The following statements by Mason and Carl were typical.

Carl: Oh, I was expecting computer studies here was like hardware. Yeah, because I would like to be a technician. 
Interviewer: OK. Mason?

Mason: I just really like computers. I want to know more about them.

For some of the boys interviewed, this approach had direct relevance to their career aspirations; for the others it was a matter of general interest. The boys favoured a computer science construction of computer studies. They were attracted to an image of "hard" computing in contrast to the "soft" computing of applications-based courses. For some, the computer-as-tool construction of the course was not delivering all they wanted or expected.

Ben: ... computer studies sort of sounded a lot more like you would learn more about the computers and putting them together, which was wrong. I thought because, you know, I thought it would teach me about the components and chucking them together and shit like - stuff like - that.

The girls taking 12CPS who were interviewed had contrasting interests and motivations for selecting 12CPS as one of their subjects. Two were drawn to the programming components of the course and particularly valued this aspect. Two had expected a course that was more in the model of text and information management and were disappointed that 12CPS was not what they expected. As a group, the students, males and females, identified 12CPS as the course for students who were interested in computers per se and in how computers work. But this was perhaps something of a misconception given the nature of the 12CPS course: the idea that computer studies involves learning about technical matters persists in the minds of students. In the words of Beth, a girl in 12TIM, computer studies is "based around the computer working and stuff ... the insides of a computer or like loading things on and stuff."

This construction of computer studies as "hard" computing does not, at first glance, have an overt gender component, other than a general association with maledominated domains of computer practice, including programming and systems management. The students did not talk directly of computer studies as a boys' subject or assume that girls could not or should not take the subject. Some of the girls interviewed saw computer studies as the specialist ICT subject most appropriate for their needs and interests. However, the notion that computer studies has a "hard" edge, characterised by an interest in the machine and the control aspects of computing, creates a masculine subjectivity. 
It seems the students perceived a hierarchy of knowledge that positioned males as more expert with and knowledgeable about computers because of their perceived interest in building computers and programming. While they acknowledged girls' ability with computers, particularly in relation to keyboarding and document production, what (some) males were doing was attributing higher status. For example, Ben, a student in 12CPS, trivialised the practices in which females engage by stating that girls "just" use computers for communication purposes and that they see it "as an extension to the telephone". By implication, he placed his own interests in "quality games", copying games, and creating web pages as superior.

The students' comments indicated that males were admired for their expertise in these areas, and when asked to identify who they thought were computer experts, they invariably identified male friends and family who were working with or had hobby interests in building computers, programming, and systems design. The students described males as having particular and peculiarly masculine computer interests, exemplified by Kathy in 12CPS, who saw what the boys did as a propensity to 'sort of go and fiddle around with the computer, see what they can find'. This notion of a masculine interest in playing with computers and knowing about and being able to control the technology was echoed by students from all three of the case study classes. For example, Matthew and Nicholas in 10TIM had this to say:

\footnotetext{
Matthew: Boys and their toys. They like being electrocuted ... They like getting electrocuted.

Interviewer: Meaning?

Nicholas: We just, like, I play round with stuff.

Matthew: Yeah. Blowing stuff up.
}

While Fiona and Angela in 12TIM commented:

Fiona: I think guys do know a lot more about computers, the actual working of them, of how they work and stuff. Like I have no idea, but I only know how to use, like, Word and stuff like that.

Interviewer: Why do you think boys know more about the actual working of them?

Angela: Boys and machines.

Fiona: Yeah [quite firm], I think, yeah. They like their games and stuff as well so they are just like, um, I don't know. It's hard to say.

Angela: I think it's sort of boys and computers and sort of like boys and cars. I think it is just their toys. I think they don't really care what they are downloading as long as they are storing something [chuckles]. They don't really care what it is. And I don't think they grow out of it either. 
Having an interest in computer technology per se and competence at building, fixing, and programming computers is presented here as something about being male. The gender identification of these particular practices creates a subtle but potent masculine subjectivity for computer studies. The students saw the course as addressing males' interests, albeit to a limited extent. In contrast, the students attributed a feminine identity to the text and information management courses. In particular, they closely associated 12TIM with typing and office practice, an area of study that the boys generally rejected as something they would not be interested in. This attitude was reflected in a dearth of males in the 12TIM class. Winifred and Beth summed up the situation:

Winifred: They [boys] think it's a girlie thing, eh?

Beth: Yeah.

Winifred: Think typing is just for girls, I think.

Beth: It is like in the sixties-you would get like mainly female secretaries and things like that.

Both the teachers and the students observed that changes to the subject had moved it away from its typing antecedent and theoretically created broader appeal for males and females. For example:

Mrs Nugent: Last year I had one [junior] class which was probably 50/50 [gender balance], and it does seem to be changing. There are more males coming into doing TIMs because I think now TIMs is perceived more as a computing course than a typing course, and I think that attracts more male students into doing, you know, into doing TIMs.

However, the students' and teachers' comments reflected a persistent association between text and information management and traditional female activities associated with office practice, particularly typing. Whether or not the boys really thought of $10 \mathrm{TIM}$ as a computing course, as Mrs Nugent suggested, is moot. Comments by the students, male and female, suggested that they saw text and information management primarily as typing. In fact, a number of students in 10TIM, 12TIM, and 12CPS repeatedly referred to these courses as "typing". This identification appeared to derive from their personal experience of text and information management courses and, in the case of some of the Year 12 students, from their participation in typing courses when they were in Year 9, or from perceptions, based on conversations with peers, of what they thought the subject was about. 
The lack of male interest in 12TIM can be explained as male resistance to the association of text and information management with typing and document production and to the concomitant attraction to particular aspects of computing addressed in computer studies. As Mr Lucas explained:

Mr Lucas: Yes, yeah. Well, of course, once they changed typing to TIM, then the structure got a bit blurred in terms of perception of what the course was. But when it was typing, boys said, 'Oh no, I'm not doing typing!' But they would do computer studies.

Mrs Keall suggested that the focus on presentation, factors relating to neatness and precision in document production, tends to appeal more to girls than to boys:

Mrs Keall: They [the girls] are more at looking, at doing-producing-something, making it look nice, that type of thing. But, yeah, we have that sort of cross-overlap in there. But in saying that, they [computer studies] are under unit standards, all of those, and we [in text and information management] have stayed clear of that really... So, yeah, not many of them went to computer studies, really. Only, mainly, a lot of the boys did. Mainly for the programming, I think. There is no, [there is] not the emphasis, on the word-processing at all.

Likewise, Mrs Nugent attributed boys' lack of interest in 10TIM to the emphasis on text production and to boys' impatience with this. In her opinion, girls are more inclined to tolerate the routine of typing.

Mrs Nugent: I don't know. I don't know whether it's [girls] wanting to please or whether it's just maybe not to question authority. I don't know. I don't know why that would be. But, generally, boys will say, 'Oh, for goodness [sake]. This is boring! Let's do something else, Miss!' You know, if that happened. Yeah.

From the tone of her observations, it was apparent that Mrs Nugent sympathised with the boys and their impatience with the typing component of 10TIM. In other comments, she indicated a desire for changes to the 10TIM course so that it would incorporate a broader range of applications and greater emphasis on design components. She implied that the current construction of 10TIM was limiting for students, confining them within an outmoded (female) typing tradition. There is a clear association, then, in the minds of teachers and students between text and information management and traditional female computing roles, interests and traits.

An association between text and information management and female work and interests was also revealed in the classroom discourse. Mrs Keall, in particular, maintained these links in her conversations with students during the 12TIM classes. She tended to use female characters and office contexts in explanations and examples 
provided to students about the relevance and applicability of 12TIM to their lives and potential work. In the following excerpt, Mrs Keall is explaining to a student how to enter records in a database.

Mrs Keall: If I want to enter a new record, I can go like that. And that's what you see on a screen. So say you're going in to get some insurance.

Lucy: Yep.

Mrs Keall: OK, the lady would say, well she's not going to ask you whether you're male or female. She should know. OK, she's going to type in M and she's going to say are you Miss, Mrs or whatever. All right? And she's going to key it in just like that. So you're going to think to yourself, is that form going to be user friendly?

Here, a fictional female character is described inputting information. Whether the use of the example of a female office worker was unconscious stereotyping or a conscious response to having an all-female class on Mrs Keall's part, the use of the female pronoun reinforces the idea that 12TIM is preparation for traditional female computer work in an office environment or related practice. Although, in interview comments, Mrs Keall acknowledged the broad range of possible work and career paths of students in 12TIM, she maintained, in the above example, an image of text and information management as preparation for office work, possibly reflecting her own background and work experience. This is a conservative and somewhat limited view, and it doubtless contributes to the creation of a feminine subject identity for text and information management.

In general, the students and teachers defined the specialist ICT subjects offered at KHS - computer studies and text and information management-through comparison and contrast with each other. The subjects had a gendered character based in historically gendered ICT traditions and curriculum domains, with computer studies emerging from a computing and mathematics foundation and text and information management from the domain of commerce and office practice. At the school level, the subjects had been constructed to cater for different student groups, with computer studies targeted at students interested in "male" computer practices and text and information management at students oriented towards practices traditionally dominated by females. The way students talked about computer studies and text and information management courses showed that they thought of these subjects as masculine and feminine subjects respectively. This is not to say that they thought computer studies was only for boys and text and information management was only 
for girls, but rather that they saw the different subjects as better serving the needs and interests of males or females. In essence, students and teachers at KHS had assigned distinct gender identifications to specialist ICT subjects in particular and the ICT curriculum in general.

\section{Discussion}

This exploration of national enrolments in specialist ICT subjects and localised ICT curriculum arrangements at a case study secondary school in New Zealand suggests that, even in an age of ubiquitous computer technology, stereotypes relating to computer use and interests remain potent and are reflected in students' subject choices and resultant gendered participation patterns. This pattern is consistent with international research (Anderson et al., in press). The case study data were gathered early in the decade and ICT subjects have evolved as technology has changed. However, as the official New Zealand Ministry of Education statistics cited in this paper show, gender differentiation continues to be a feature of participation patterns in ICT subjects. The case study data helps us to understand and explain this phenomenon.

More specifically, this multi-faceted study reveals that gender socialisation and identity construction is just as powerful an underlying force behind apparent gender inequities relating to computer interests and education in this first decade of the new millennium as it was in previous decades. This premise is supported in the international literature that describes links between gender identity and technological competence, with hegemonic masculinity in particular being tied up with notions of technological competence and control (Jenson, de Castell, \& Bryson, 2003; Schofield, 1995; Wajcman, 1994), and with educational success associated with notions of masculine rationality (Gilbert, 2005). The alienation of females from computing is explained as a product of the social construction of masculinity and the historical and cultural construction of computing as masculine practice (Clegg, 2001; Grint \& Gill, 1995).

Thus, it is suggested that the social construction of male and female domains of computer practice and the propensity for permissive curriculum arrangements such as 
those "used" in New Zealand to sustain these domains is an underlying factor in persistent gender participation patterns in ICT education and careers. Where a domain of practice and different subjects are distinctly and strongly gender identified, as is the case with ICT, male and female gender constructions seem to be pitted against each other in the subject offerings to students. There is potential to challenge or to sustain gender stereotypes through the subjects on offer. However, where the proffered subjects derive from gendered traditions and are seen to originate from these traditions by those who are making the choices, the effect of the choice is to maintain and sustain gender stereotypes and the status quo of a gendered curriculum.

In New Zealand, the flexibility for schools and teachers to develop their own courses has been taken up in a way that reinforces gendered subjectivities. This is not to say that all schools and all teachers take the conservative route and construct their curriculum on gendered lines. However, the KHS case study shows that, for some schools at least, flexibility in the curriculum and ostensible attempts to cater for students' interests in the construction of the ICT curriculum at school level perpetuate gender stereotypes, with some subjects positioned as more suitable or appropriate for boys or for girls, however unconsciously and unintentionally this may be done.

Choice and flexibility in this context is part of the problem. Rather than challenge gender differences, these factors act to sustain gender differences and potential inequities. This is the paradox of choice, where the outcome may restrict options and possibilities for students rather than open new horizons for ICT involvement and education. It is not that choice per se is bad, but rather that the nature of the choice is very important if teachers, schools, and curriculum developers are to provide a curriculum where the flexibility in the curriculum is directed at challenging gender stereotypes rather than sustaining them. In New Zealand, the devolution of responsibility to schools to decide the nature of the ICT curriculum at the local level may be viewed as a democratic process that empowers teachers and communities, but this empowerment may not have the desired effect in respect of future thinking directed at ICT curriculum construction. Whether or not the curriculum at school level is innovative and the subjects on offer challenge gender stereotypes may be as much a matter of chance as it is of design - a matter of fortuity relating to staffing arrangements and the backgrounds and experiences of those who have responsibility 
for curriculum development and the design of specialist ICT courses in particular schools.

The ad hoc nature of national ICT curriculum development in New Zealand has resulted in a multiplicity of guidelines for different ICT components, including the broad statements relating to the technology learning area in the national curriculum and the specific requirement for achievement standards and unit standards for national certificate qualifications, with the latter constituting a de facto curriculum at senior secondary levels. This situation provides options for schools but does little to give cohesion to the ICT curriculum or to provide a mechanism for addressing gender issues in local curriculum construction. Gender constructions are not immutable, nor do they change overnight. There is no easy fix to deeply entrenched social phenomena. A starting point for addressing perceived inequities in male and female ICT participation may be greater coordination of the ICT curriculum at a national level, without reverting to national prescription that leaves little room for local innovation. This is something for which national policymakers need to take responsibility.

However, national curriculum review is easier said than done, and it may therefore be more manageable and feasible to focus on the assessment mechanisms in the achievement standards reviews. The discrete nature and multiplicity of standards presents issues of choice for schools and teachers because the latter create their own unique ICT subjects and curriculum in practice. This option, though, is a pragmatic rather than a principled one. Big questions need to be addressed about the nature and role of a national curriculum, the position of specialist senior subjects in that curriculum, and the tension between flexibility for schools in curriculum construction and the responsibility of national bodies to provide guidance and direction.

Others who can play a part include teacher-educators and those who lead professional development with practising teachers. These people may be able to make a difference - at least in the short term - and, even if small in scope, by sensitising those responsible for the curriculum in practice to issues of gender and curriculum choice. They can heed calls in international literature to rethink how ICT is framed in schools and wider educational contexts (see, for example, the American Association 
of University Women Educational Foundation Commission on Technology, 2000; Clegg \& Trayhurn, 2000; Cukier et al., 2002; Margolis \& Fisher, 2002). Accordingly, an invitation is given here to teachers to think carefully about the nature of the courses and the choice of ICT subjects they present to students.

Although the context of the research presented in this paper is the New Zealand curriculum, the implications of its findings are further reaching because they link persistent gender differences in subject participation to socialisation processes and broad curriculum structures. International literature identifies a litany of factors that influence gendered student participation patterns in ICT courses, including student confidence and previous computer experience, the image held of ICT subjects and stereotypes of "computer nerds", software bias, lack of female role models, and lack of knowledge about ICT careers (Anderson et al., in press; Colley \& Comber, 2003; Margolis \& Fisher, 2002). These factors help to explain gendered patterns in student choices of ICT subjects and career paths. But alongside them, we also need to place broader considerations of gendered subjectivities, curriculum structures, and the nature of choices inherent in curriculum arrangements.

\section{References}

Abbiss, J. (2006). Learning from students' experiences of IT courses. Computers in New Zealand Schools, 18(3), 34-41.

American Association of University Women Educational Foundation Commission on Technology. (2000). Tech-savvy: Educating girls in the new computer age. Washington DC: Author.

Anfara, V., Brown, K., \& Mangione, T. (2002). Qualitative analysis on stage: Making the research process more public. Educational Researcher, 31(7), 28-38.

Anderson, N., Lankshear, C., Timms, C., \& Courtney, L. (in press). "Because it's boring, irrelevant and I don't like computers": Why high school girls avoid professionally-oriented ICT subjects. Computers and Education.

Beynon, J., \& Mackay, H. (Eds.). (1993). Computers into classrooms: More questions than answers. London: The Falmer Press.

Bogdan, R., \& Biklen, S. (1998). Qualitative research for education: An introduction to theory and methods (3rd ed.). Boston, MA: Allyn and Bacon. 
Brown, M., \& Chamberlain, M. (2003). National policies and practices on ICT in education: New Zealand. In T. Plomp, R. E. Anderson, N. Law, \& A. Quale (Eds.), Cross national information and communication technology policies and practices in education (pp. 411-426). Greenwich, Connecticut: Information Age Publishing.

Butler, G. (1996). ImpacT 2001: How information technology will change New Zealand (report prepared for the Information Technology Advisory Group and the Information Technology Association of New Zealand). Wellington: Information Technology Advisory Group.

Chen, M. (1986). Gender and computers: The beneficial effects of experience on attitudes. Journal of Educational Computing Research, 2(2), 265-282.

Clegg, S. (2001). Theorising the machine: Gender, education and computing. Gender and Education, 13(3), 307-324.

Clegg, S., \& Trayhurn, D. (2000). Gender and computing: Not the same old problem. British Educational Research Journal, 26(1), 75-90.

Coffey, A., \& Atkinson, P. (1996). Making sense of qualitative data: Complementary research strategies. Thousand Oaks: Sage Publications.

Colley, A., \& Comber, C. (2003). Age and gender differences in computer use and attitudes among secondary school students: What has changed? Educational Research, 45(2), 155-165.

Creswell, J. (1998). Qualitative inquiry and research design: Choosing among five traditions. Thousand Oaks: Sage Publications.

Cukier, W., Shortt, D., \& Devine, I. (2002). Gender and information technology: Implications of definitions. Journal of Information Systems Education, 13(1), $7-16$.

Culley, L. (1993). Gender equity and computing in secondary schools: Issues and strategies for teachers. In J. Beynon \& H. Mackay (Eds.), Computers into classrooms: More questions than answers (pp. 147-159). London: The Falmer Press.

Davis, D., Broege, S., Steinmetz, R., \& Raman, V. (2006). Gender differences in new media use: New Zealand, Germany, and the US. Paper presented at the annual meeting of the International Communication Association, Dresden 
International Congress Center, Dresden, Germany, June 16, 2006. Available on http://www.allacademic.com/meta/p91953_index.html.

Denzin, N., \& Lincoln, Y. (Eds.). (1998a). Introduction: Entering the field of qualitative research. In N. Denzin \& Y. Lincoln (Eds.), Collecting and interpreting qualitative materials (pp. 1-34), Thousand Oaks, CA: Sage Publications.

Denzin, N., \& Lincoln, Y. (1998b). The landscape of qualitative research: Theories and issues. Thousand Oaks, CA: Sage Publications.

Durndell, A., Glissov, P., \& Siann, G. (1995). Gender and computing: Persisting differences. Educational Research, 37(3), 219-227.

Gilbert, J. (2005). Catching the knowledge wave? The knowledge society and the future of education. Wellington: NZCER Press.

Grint, K., \& Gill, R. (Eds.). (1995). The gender-technology relation: Contemporary theory and research. London: Taylor and Francis.

Holliday, A. (2002). Doing and writing qualitative research. London: Sage Publications.

Holstein, J., \& Gubrium, J. (1998). Phenomenology, ethnomethodology, and interpretive practice. In N. Denzin \& Y. Lincoln (Eds.), Strategies of qualitative inquiry (pp. 137-157). Thousand Oaks, CA: Sage Publications.

Hoyles, C. (Ed.). (1988). Girls and computers. London: Institute of Education.

Jackson, M. (1996). Introduction: Phenomenology, radical empiricism, and anthropological critique. In M. Jackson (Ed.), Things as they are: New directions in phenomenological anthropology (pp. 1-50). Bloomington: Indiana University Press.

Jenson, J., de Castell, S., \& Bryson, M. (2003). "Girl talk”: Gender, equity, and identity discourses in a school-based computer culture. Women's Studies International Forum, 26(6), 561-573.

Johnson, N. (2006). Boys and girls are the same: Gender perceptions in using computers in the classroom. Computers in New Zealand Schools, 18(3), 5-11, 33.

Kenway, J. (1998). Pulp fictions? Education, markets, and the information superhighway. In D. Carlson \& M. Apple (Eds.), Power/knowledge/pedagogy (pp. 61-91). Boulder, CO: Westview Press. 
Law, N. Pelgrum, W. J., \& Plomp, T. J. (2008). Pedagogy and ICT use in schools and around the world: Findings from the IEA SITES 2006 study. Hong Kong: Comparative Education Research Centre, University of Hong Kong.

Lewis, B., Smith, R., \& Jenson, J. (2001). Is policy important? Technology policy and its practices in $\mathrm{K}-12$ education in Canada. Paper presented at the annual meeting of the American Educational Research Association, Seattle, WA, April 10-14.

Logan, K. (2007). Should computing be taught in single-sex environments? An analysis of the computing learning environment of upper secondary students. Educational Studies, 33(2), 233-248.

Margolis, J., \& Fisher, A. (2002). Unlocking the clubhouse: Women in computing. Cambridge, MA: The MIT Press.

Margolis, J., Fisher, A., \& Miller, F. (2000). Caring about connections: Gender and computing. IEEE Technology and Society Magazine, Winter 1999/2000, 1320.

McKinnon, D., \& Nolan, P. (1990). Curriculum innovation with computers: Redressing inequalities of access and use in the Freyberg integrated studies project. In A. McDougall \& C. Dowling (Eds.), Computers in education: Proceedings of the IFIP TC 3 fifth world conference in education-WCCE 90, Sydney, Australia, July 9-13, 1990 (pp. 145-153). Amsterdam: Elsevier Science Publishers.

Ministry of Education. (1995). Technology in the New Zealand Curriculum.

Wellington: Learning Media.

Ministry of Education. (2002). Digital horizons: Learning through ICT: A strategy for schools, 2002-2004. Wellington: Author.

Ministry of Education. (2007). The New Zealand Curriculum. Wellington: Learning Media.

Mitra, A., LaFrance, B., \& McCullough, S. (2001). Differences in attitudes between women and men toward computerization. Journal of Educational Computing Research, 24(3), 227-244.

Moursund, D. (1997). The future of information technology in education. Eugene, OR: International Society for Technology in Education. 
O’Neill, J. (2003). Information and communication technologies: An iconography unplugged. Computers in New Zealand Schools, 15(2), 6-9.

Pelgrum, W., \& Anderson, R. (Eds.). (1999). ICT and the emerging paradigm for lifelong learning: A worldwide educational assessment of infrastructure, goals and practices. Enschede: Printpartners Ipskamp.

Ryba, K., \& Selby, L. (1995). A study of tertiary level information technology courses: How gender inclusive is the curriculum? Final report. Wellington: Ministry of Education.

Sallis, P. (1990). Report of the Consultative Committee on Information Technology in the School Curriculum. Wellington: Ministry of Education.

Schofield, J. W. (1995). Computers and classroom culture. Cambridge: Cambridge University Press.

Selby, L. (1995). Where have all the young women in computing gone? Computers in New Zealand Schools, 7(3), 25-27.

Seybert, H. (2007). Gender differences in the use of computers and the Internet. Statistics in focus: Population and social conditions, 119/2007. Luxembourg: Eurostat, European Communities.

Stake, R. (1998). Case studies. In N. Denzin \& Y. Lincoln (Eds.), Strategies of qualitative inquiry (pp. 86-109). Thousand Oaks, CA: Sage Publications.

St. Pierre, E. A. (2002). Circling the text: Nomadic writing practices. In N. Denzin \& Y. Lincoln (Eds.), The qualitative inquiry reader (pp. 51-69). Thousand Oaks, CA: Sage Publications.

Tashakkori, A., \& Teddlie, C. (Eds.). (2003). Handbook of mixed methods in social and behavioural research. Thousand Oaks, CA: Sage Publications.

United Nations Conference on Trade and Development. (2002). E-commerce and development report 2002. New York: United Nations.

Wajcman, J. (1991). Feminism confronts technology. Oxford: Polity Press.

Wajcman, J. (1994). Technological a/genders: Technology, culture and class. In L. Green \& R. Guinery (Eds.), Framing technology: Society, choice and change (pp. 3-14). St Leonards, NSW: Allen and Unwin.

Yin, R. (1994). Case study research: Design and methods (2nd ed.). Thousand Oaks, CA: Sage Publications. 
